REVISTA DE GESTÃO ESECRETARIADO

MANAGEMENT AND ADMINISTRATIVE

PROFESSIONAL REVIEW

ISSN: 2178-9010
Revista GeSec

São Paulo, SP, Brasil

v. 12 , n. 1, p. 231-257

jan. /abr. 2021

DOI: http://dx.doi.org/10.7769/gesec.v12i1.1152

\title{
Projeto aprovado: e agora, como contratar o gerente de projetos ideal?
}

\section{Approved project: and now, how to hire the ideal project manager?}

\author{
Nadia Pedrosa ${ }^{1}$ \\ Luciano Ferreira da Silva ${ }^{2}$ \\ Cristina Dai Prá Martens ${ }^{3}$
}

\section{Resumo}

Este artigo abrange questões amplas sobre o processo de contratação do gerente de projetos (GP) do segmento de Tecnologia da Informação (TI) no Brasil. Esse tema surgiu da necessidade de entender como se dá tal processo nas empresas sob a ótica do executivo de TI (ETI), que é o tomador de decisão na escolha do candidato ideal para ocupar o cargo de gerente de projetos de TI (GPTI). Nossa motivação para estudar esse tema nasceu da constatação de que o desempenho dos projetos depende mormente da figura do GP e, portanto, fazer uma boa contratação significa começar bem um projeto de sucesso. O objetivo deste artigo foi apresentar as etapas do processo de contratação do GP sob a ótica do ETI. Isso só foi possível após extensa revisão de literatura e 16 entrevistas com ETI dos estados de São Paulo e Minas Gerais. Nossos resultados demonstraram que o fenômeno da contratação do GPTI é feito sob improvisos e empirismo. As contribuições teóricas residem em nossa agenda de pesquisas futuras sobre o tema. As contribuições práticas residem na lista de prescrições para os ETI e GPTI interessados em tirar o melhor proveito do processo de contratação.

Palavras-chave: Contratação. Gerente de Projetos. Tecnologia da Informação. Soft Skills.

\section{Abstract}

This article covers broad questions about the process of hiring the project manager (PM) for the Information Technology (IT) segment in Brazil. This theme arose from the need to

\footnotetext{
${ }^{1}$ Doutoranda no Programa de Pós-Graduação em Administração da Universidade Nove de Julho (Uninove).

2 Doutor em Administração, Docente no Mestrado Profissional em Administração da Uninove.

3 Doutora em Administração, Docente no Mestrado Profissional em Administração e no Programa de PósGraduação em Administração da Uninove.
} 
understand how the process in companies from the perspective of the IT executive (ITE), which is to make the decision to choose the ideal candidate to occupy the position of IT project manager (ITPM). Our motivation to study this theme was born from the realization that the performance of the projects depends more on the figure of the project manager and, therefore, making a good contract means starting a successful project well. The purpose of this article was presented as steps in the process of hiring the project manager from the perspective of ITE. This was possible after a literature review and 16 interviews with the ITEs of the states of São Paulo and Minas Gerais. Our results demonstrate that the ITPM contracting phenomenon is carried out under improvisation and empiricism. Theoretical contributions lie on our agenda for future research on the topic. The practical contributions lie in the list of prescriptions for ITEs and ITPMs interested in removing or improving the contracting process.

Keywords: Hiring. Project Manager. Information Technology. Soft Skills.

\section{Introdução}

A contratação do GP é uma etapa importante na gestão de projetos. A literatura preconiza que as competências do GP influenciam positivamente os resultados do projeto (Pant and Baroudi, 2008; Stevenson and Starkweather, 2010; Blomquist, Farashah and Thomas, 2016; Cassar and Martin, 2016). Por esta razão, quando um projeto é aprovado, torna-se condição imperativa a escolha acertada do GP. Segundo Mantovani (2020), o mercado estará mais exigente nas contratações, não haverá grandes aumentos salariais, mas as oportunidades existirão para aqueles que valorizaram o planejamento da carreira. Para $48 \%$ dos líderes entrevistados pela pesquisa salarial Robert Half, é um desafio significativo encontrar profissionais qualificados e a expectativa para 2024 é que o grau de dificuldade para contratar se mantenha alto. A mesma pesquisa mostrou que $81 \%$ dos líderes afirmam que a área da tecnologia é a mais afetada pela carência de bons candidatos, haja vista, muitos profissionais não acompanharem o avanço tecnológico (Robert Half, 2020).

A área de tecnologia não sofreu grandes consequências com o cenário político e econômico do Brasil dos últimos anos, pois a mesma deixou de ser vista como um centro de custo e passou a ser vista como um importante otimizador dos negócios (Hays, 2019). O aquecimento do mercado brasileiro de tecnologia da informação (TI) se dá pelo aumento no número de posições em aberto, principalmente em empresas de e-commerce e fintechs. A área 
de projetos está em uma curva crescente graças à transformação digital, assim como a valorização de áreas, como: inteligência artificial, ciência de dados, business intelligence e analytics (PageGroup, 2019). Tal cenário promissor justifica a nossa escolha em pesquisar a indústria de TI no Brasil.

Embora haja muitos estudos sobre os fatores críticos de sucesso em projetos (Shenhar et al., 2001, 2007), as estatísticas ainda não são boas. Cerca de 33\% a 65\% de todos os projetos de TI resultam em excedentes de custo e tempo e geram produtos ou serviços aquém das expectativas dos clientes (Singh, Keil and Kasi, 2009). Replanejamentos de prazo, mudanças de escopo, clientes insatisfeitos com a qualidade do resultado do projeto fazem emergir uma dúvida quanto à eficiência da gestão de projetos. Em paralelo, o gerenciamento de projetos é uma carreira para a qual cada vez mais pessoas são recrutadas (Havermans et al., 2019). Por conseguinte, escolheu-se o fenômeno da contratação do GP como alvo desta pesquisa para investigar se as organizações estão começando bem seus projetos.

Partiu-se da premissa de que a tarefa de tomar a decisão na hora de contratar o gerente de projetos de TI (GPTI) recaia sobre o executivo de TI (ETI). Escolhas malsucedidas na contratação do GP poderão influenciar negativamente os resultados do projeto. Fatores relacionados à personalidade do GPTI podem influenciar diretamente nos indicadores de sucesso do projeto (Bevilacqua et al., 2014). Além disso, a contratação é tida como um processo amplamente estudado, mas ainda pouco compreendido (Petersen, Saporta and Seidel, 2000). A partir dessa problematização surgiu a questão que guiará esta pesquisa: Como é o processo de contratação do gerente de projetos de TI sob a ótica do executivo de TI? Acredita-se que ao entender tal processo, pode-se explicitar problemas enraizados nas empresas quanto ao processo de contratação do GPTI. O objetivo deste artigo é apresentar as etapas do processo de contratação do GPTI sob a ótica do ETI.

O presente artigo foi construído com base na realização de uma revisão da literatura para identificação do estado da arte sobre a contratação do GP. Uma rodada foi realizada posteriormente com 16 entrevistas com ETI nos estados de São Paulo e Minas Gerais. A partir de então, foi possível identificar as principais características do processo de contratação do GPTI, mapeá-las e apresentá-las na seção de resultados. Ao expandir o conhecimento sobre o processo de contratação do GPTI é possível avançar no campo de pesquisa sobre gestão de recursos humanos $(\mathrm{RH})$. Nossa contribuição teórica reside nos achados desta pesquisa, pois acredita-se que eles possam iluminar novas questões de pesquisa para estudiosos. Nossa 
contribuição prática reside na lista de prescrições para o ETI e para o GPTI como forma de melhorar a sistemática de recrutamento e seleção do candidato à vaga de GPTI.

\section{Referencial Teórico}

\subsection{Gerente de Projetos}

Projeto é uma unidade organizacional dedicada ao cumprimento de uma meta, em geral, a conclusão bem-sucedida de um produto ou serviço no prazo, dentro do orçamento e em conformidade com especificações predeterminadas (PMI, 2017). Em uma atualização da definição, Paton, Hodgson e Cicmil (2010) descrevem projeto como meio para entregar novos produtos, inovações e canalizar mudanças em ambientes de negócios incertos e de intenso conhecimento. Havermans et al. (2019) associam o projeto a um importante instrumento de mudança e, consequentemente, o GP é um agente da gestão de mudanças.

O papel do GP é desafiador por ocupar uma situação insegura, com pouca autoridade e operando fora da estrutura hierárquica da organização (Richardson, Earnhardt and Marion, 2015). Uma de suas funções é integrar as partes interessadas e conciliá-las para o alcance dos objetivos do projeto numa visão de curto prazo (Camarini and Sousa, 2006). Gaddis (1959) cita que um dever importante do GP, que se mantém atual nos dias de hoje, é evitar as crises durante os estágios de planejamento, desenvolvimento e verificação do projeto (Lima, 2016). Liderança, gestão efetiva do tempo, habilidades interpessoais e comunicação compõem as habilidades que um bom GP deve ter (Kang et al., 2005).

Gerentes de projetos competentes têm impacto positivo no sucesso do projeto (Hauschildt, Keim and Medcof, 2000) e, por sua vez, no sucesso dos negócios (Keegan, Ringhofer and Huemann, 2017). Suas funções exigem uma ampla gama de competências pessoais, humanas, conceituais, organizacionais e técnicas (Havermans et al., 2019). Apesar de sua essência técnica, a área de TI tem demonstrado uma ampliação na busca por profissionais com competências comportamentais (Skulmoski and Hartman, 2010; Stevenson and Starkweather, 2010). Os pesquisadores têm debatido sobre quais dessas competências podem reduzir as falhas em projetos (Bevilacqua et al., 2014).

Em linhas gerais, um GP bem sucedido deve possuir habilidades como hard skills e soft skills (Pinto, Patanakul and Pinto, 2015). Os hard skills são constituídos pelo conhecimento, 
pela experiência e pelo alicerce tecnológico, e os soft skills são reconhecidos como pensamento criativo, integridade pessoal, automotivação e habilidades comunicativas (Uzoka et al., 2018). A dicotomização das competências entre hard skills e soft skills, à primeira vista, parece traçar caminhos paralelos de perfil profissional; contudo, elas são complementares (Pinto, Patanakul and Pinto, 2017). Embora existam comunalidades nas competências do GP, há disparidades em seu perfil que são demandadas por diferentes indústrias (Stevenson and Starkweather, 2010). Cheng, Dainty e Moore (2005) explicam que os hard skills são específicos, pois variam de acordo com a indústria. Já os soft skills são genéricos e independem da indústria alvo do GP.

Os empregadores da área de TI esperam contratar profissionais com habilidades tecnológicas específicas, mas valorizam as habilidades não técnicas, até mais que as técnicas (Uzoka et al., 2018). A avaliação dos candidatos à vaga de GP passou a ter uma nova preocupação: os soft skills. Em seu estudo com ETI, Stevenson e Starkweather (2010) apresentam as competências mais relevantes para os GPTI: 1 $1^{\mathrm{a}}$ - liderança, $2^{\mathrm{a}}$ - habilidade de comunicação em múltiplos níveis, $3^{\mathrm{a}}$ - habilidade de comunicação verbal, $4^{\mathrm{a}}$ - habilidade de comunicação escrita, $5^{\text {a }}$ - atitude e $6^{\text {a }}$ - habilidade em lidar com ambiguidade e mudança. Destaca-se que as seis competências são soft skills. Napier, Keil e Tan (2009), em seu estudo sobre competências do GPTI, destacaram as seguintes: (a) integridade pessoal, (b) desenvolvimento de equipe, (c) gerenciamento de clientes, (d) planejamento e controle e (e) solução de problemas. Na classificação das habilidades mais importantes do GPTI, os autores identificaram 19 essenciais, entre elas, as que ficaram no topo do ranking foram: $\left(1^{\circ}\right)$ liderança, $\left(2^{\circ}\right)$ comunicação verbal, $\left(3^{\circ}\right)$ gerenciamento de escopo, $\left(4^{\circ}\right)$ escuta e $\left(5^{\circ}\right)$ planejamento de projetos.

\subsection{Contratação do Gerente de Projetos}

O processo de contratação talvez seja o elo mais importante na relação de trabalho entre empregados e empregadores. Trata-se de um processo complexo (Petersen, Saporta and Seidel, 2000), subjetivo, cheio de estereótipos e de vieses (Kulik, Roberson and Perry, 2007), especialmente por se tratar de partes que raramente se conhecem bem, que têm informações limitadas sobre o que a outra parte faz e pensa. Para Petersen et al. (2000), a contratação envolve três estágios: $\left(1^{\circ}\right)$ o processo de recrutamento; $\left(2^{\circ}\right)$ o processo de oferta; e, $\left(3^{\circ}\right)$ negociação da oferta. 
Apesar de sua importância, o processo de contratação é a parte mais incompreendida da relação de trabalho (Petersen, Saporta and Seidel, 2000). Kulik et al. (2007) afirmam que a percepção e o julgamento social que o recrutador faz sobre o candidato influencia, de maneira inconsciente e automática, na tomada de decisão do processo de contratação. Pesquisa com 304 alunos de um curso de MBA no Brasil mostrou que até mesmo o sotaque do candidato conta no processo de contratação, evidenciando que é um processo suscetível a julgamentos irracionais e estigmatizados (Araujo, Correa, \& Wolters, 2016). O aspecto subjetivo do tomador de decisão aumenta o risco da escolha da pessoa errada em um processo seletivo (Cassar and Martin, 2016).

Diante do fenômeno da projetização das organizações (Midler, 1995), mais e mais praticantes estão se enveredando por carreiras em torno da gestão de projetos (Pinto, Patanakul and Pinto, 2015). Isso pode ser especialmente perigoso para o gerenciamento de projetos, porque as pessoas tendem a se encaixar na profissão e recebem pouca ou nenhuma preparação para a realização do trabalho, resultando no rótulo de 'profissão acidental' (Richardson, Earnhardt and Marion, 2015). Tal fato traz à luz a importância da contratação dos gerentes de projetos.

A contratação do GP deveria começar com a compreensão das características do GP ideal. Atributos como: flexibilidade, iniciativa, confiança, ambição, entusiasmo, disciplina e espontaneidade são apenas alguns exemplos citados pela longa lista publicada por Hauschildt et al. (2000). Entretanto, esses mesmos autores concluíram que essas características são raramente encontradas juntas em um indivíduo do mundo real e, então, sugerem um conhecimento da natureza do projeto e definição dos atributos do GP ideais para cada tipo de projeto (Hauschildt, Keim and Medcof, 2000).

Uma característica da atuação do GP é que seu trabalho é limitado em duração, dada a própria natureza temporária do projeto (PMI, 2017). Tal cenário reflete em contratações do GPTI com características temporárias para cobrir uma demanda enquanto durarem os projetos nas empresas. Essa tendência foi ratificada no relatório da PageGroup (2019) que demonstra que $21 \%$ dos contratos, no Brasil, são temporários. Outrossim, o trabalho de Prado e Takaoka (2002) revelou que as organizações estão terceirizando mais e mais as atividades ligadas à TI, baseadas em motivadores econômicos. 
Para atrair e reter profissionais de qualidade, Kang et al. (2005) recomendam que haja uma boa oferta salarial, o que nem sempre é possível nas empresas. Outro desafio é fazer com que a divulgação da vaga chegue até os bons profissionais, por meio de múltiplos canais (Kang et al., 2005). Um vilão do processo de contratação é a disponibilidade de tempo dos recrutadores que, em geral, estão ocupados com outras atividades do dia a dia das empresas.

A entrevista é o método tradicional mais usado para avaliar o candidato à vaga de GP. A seleção é baseada na percepção do recrutador quanto às competências do GP e provável perfil para gerenciar determinado projeto. Em geral, um grupo de especialistas participa da entrevista como avaliadores o que introduz incertezas, vieses, erros e ambiguidade ao processo de contratação (Cassar and Martin, 2016).

\section{Metodologia}

Este estudo adotou abordagem qualitativa com uma perspectiva exploratória (Creswell, 2010). Foram realizadas entrevistas presenciais, com perguntas abertas, para 16 ETI nos estados de São Paulo e Minas Gerais para compor o entendimento do processo de contratação do GPTI.

Os entrevistados foram selecionados por conveniência e também por meio da técnica de bola de neve (Goodman, 1961), mas todos atendiam ao requisito obrigatório: participar ativamente da contratação e ser forte influenciador na escolha do candidato à vaga de GPTI em sua empresa. Esta pesquisa não entrevistou profissionais da área de RH dada a premissa de que são os ETIs (líderes, gerentes, diretores, ou seja, os gestores do GP) que fazem a escolha do GP.

A entrevista buscou ressaltar principalmente três tópicos: (1) Descrição do processo de contratação, visando entender, de maneira holística, como ocorria o processo de contratação do GPTI; (2) Desafios que permeiam o processo na contratação do GPTI; e, (3) Requisitos do candidato à vaga de GPTI mais demandados pelos ETI. As entrevistas foram gravadas, com o consentimento dos ETI, e depois transcritas manualmente, e importadas no ATLAS.ti ferramenta de análise qualitativa de dados assistida por computador usada como apoio à análise dos dados (Bandeira-de-Mello, 2006). 
O processo de contratação do GPTI é o fenômeno alvo dessa pesquisa. Dada a natureza subjetiva e processual deste fenômeno, fez-se uso da técnica de Grounded Theory, que se baseia em alicerçar os resultados da pesquisa nos dados (Charmaz, 2006). A adoção dessa técnica permitiu um entendimento mais aprofundado do fenômeno estudado (Charmaz, 2006), além de possibilitar a revelação de prescrições para que os ETI e GPTI melhorem sua atuação no processo de contratação. O ciclo das 16 entrevistas foi finalizado após constatação de que novas informações não surgiram nas últimas duas entrevistas. Para evitar o viés do pesquisador, garantimos a credibilidade dos resultados por meio da análise de dados aos pares (Alam, 2005): um pesquisador analisou os dados e um segundo, mais sênior, com experiência em métodos qualitativos, revisou e discutiu os resultados deixando-os mais refinados e robustos.

O processo de codificação foi a parte central da análise dos dados, realizado em três etapas: $\left(1^{\text {a }}\right)$ codificação aberta caracterizada pela criação de códigos de dados que levou a criação inicialmente de 110 codes e 776 quotations; $\left(2^{\mathrm{a}}\right)$ codificação axial responsável pela análise das relações de causalidade entre as categorias que resultou em 147 codes e 1.016 quotations; e, $\left(3^{\mathrm{a}}\right)$ codificação seletiva que permitiu identificar a categoria central da teoria e refinar as relações desta com todas as outras categorias que culminou com a criação de 4 network views (Bandeira-de-Mello and Cunha, 2003).

\section{Análise e Discussão Dos Resultados}

\subsection{Processo de Contratação do GPTI}

A partir das entrevistas, alguns aspectos demográficos foram destacados: os ETI entrevistados têm em média 46 anos de idade, 25\% são mulheres, 75\% homens e, em média, eles possuíam 15 anos de experiência com gestão de projetos. Os ETI atuam em empresas de diferentes segmentos de negócio, a maioria é da indústria de TI, mas houve representantes de: agronegócio, meios de pagamento, varejo, tecnologia, instituição financeira, consultoria em gestão de projetos e aviação. As perguntas foram elaboradas a partir da literatura pesquisada e seguiram um roteiro semiestruturado. Os 16 entrevistados descreveram o processo de contratação do GPTI em suas organizações. Apesar de apresentarem processos próprios bem peculiares, foi possível constatar que os métodos de contratação declarados pelos ETI de diferentes segmentos de empresas são similares e possuem etapas ordenadas semelhantes. 
$1^{\text {a }}$ Etapa - Definição do perfil da vaga

Nesta primeira parte do processo, os ETI iniciam a contratação do GPTI com a definição do perfil da vaga. O Entrevistado 8 resumiu da seguinte forma essa etapa: “ $O s$ detalhes, os requisitos da vaga dependem muito pra que posição ele [gerente de projetos] vai ocupar. Mas, de uma forma geral é: graduação, especialização em gestão de projetos, experiência de, no mínimo, 5 anos e eu também coloco requisitos humanos e pessoais".

O perfil técnico e comportamental é elaborado mediante o entendimento da natureza do projeto e seus atributos como: objetivo, complexidade, orçamento, o perfil do requisitante do projeto e dos principais membros da equipe do projeto que irão atuar com o futuro GPTI. Quanto mais o ETI compreender a demanda, melhor será a definição do perfil da vaga. O requisitante do projeto pode ser do departamento de TI, ou pertencer à outra área funcional da organização ou ainda pertencer a uma empresa externa. Com base nas entrevistas, de acordo com os ETI, o perfil da vaga deve abranger: (1) Formação acadêmica do GP; (2) Nível do GP (sênior, pleno, júnior); (3) Experiência anterior com projetos semelhantes ao da vaga; (4) Conhecimento em tecnologias (SAP, Big data, IoT, etc.); (5) Tempo de experiência em gerenciamento de projetos; (6) Conhecimento em idiomas; (7) Soft skills requeridos; (8) Situação atual do projeto; (9) Necessidade de possuir certificações de instuições renomadas em gerenciamento de projetos e (10) Conhecimento do negócio; Modalidade de contratação.

Depois de realizada a definição do perfil da vaga (informação que será publicada), o ETI propõe a descrição da vaga (informação interna), que é comumente conhecida como job description. A descrição da vaga não deve contemplar todos os requisitos para não inspirar o candidato a assumir diferentes perfis na entrevista, conforme explicou o Entrevistado 11: "Porque uma coisa é o que eu busco, outra coisa é o que é escrito. [...] tem coisas que eu busco numa entrevista e que jamais poderão estar escritas na vaga porque eu não quero que o candidato saiba. Tem os requisitos declarados e tem os requisitos não declarados".

\section{$2^{a}$ Etapa - Divulgação da vaga}

Diante do perfil do candidato à GPTI definido pelo ETI, o próximo passo é divulgar a vaga. Os 16 ETIs entrevistados alegaram que delegam essa atividade para seu departamento de RH ou para empresa subcontratada. A divulgação da vaga é feita em canais online como LinkedIn, Apinfo, Catho, entre outros. Os candidatos enviam seus currículos via canais digitais e o RH faz uma seleção prévia dos mais aderentes ao perfil da vaga.

O RH realiza essa triagem e seleciona alguns candidatos para a primeira entrevista e verifica aspectos mais amplos do perfil do candidato, como: aderência à cultura da empresa, 
expectativa salarial, disponibilidade para início, momento de vida do candidato e objetivos de carreira. Em geral, o RH é o responsável também pela aplicação de testes de análise comportamental e de conhecimentos técnicos em gestão de projetos - quando cabível.

Os testes psicológicos usados para avaliar o perfil comportamental dos candidatos aplicados pelo RH, citados pelos ETI, são: Dominance, Influence, Steadiness e Compliance (DISC), Myers Briggs Type Indicator (MBTI) e Predictive Index (PI) Na sequência, os candidatos pré-selecionados pelo RH, seguem para uma avaliação mais detalhada pelo ETI. A explicação dessa etapa foi resumida pelo Entrevistado 7: "Então, ela [área de RH] faz essa primeira olhada, que é um olhar de RH. Então, ela só chama aquelas pessoas que têm as características técnicas que nós estamos buscando [...], faz a triagem através das entrevistas pra enxergar se aquele profissional tem o modus operandi da empresa. Depois que ela faz esse processo, ela separa cinco profissionais que aí sim, ela manda pra nós [executivos de $\mathrm{TI}$ ]". O mesmo cenário repercutiu no discurso do Entrevistado 14: "E aí, o grupo de recrutamento e seleção que é uma área dentro do nosso $R H$, começa divulgando as vagas em várias redes sociais, [...] começa a receber os currículos, fazer a triagem, faz uma seleção, faz uma entrevista do recrutamento e seleção com o candidato. [...] tendo os requisitos da vaga, tendo interesse e disponibilidade, agenda uma entrevista técnica comigo [executivo de $\mathrm{TI}] "$.

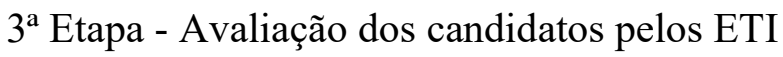

Nesta última etapa, os ETI realizam avaliações dos hard skills e soft skills dos candidatos previamente triados pelo RH. No quesito hard skills, conhecimentos em gestão de projetos é o foco da avaliação. No quesito soft skills, o ETI procura avaliar as habilidades interpessoais do candidato, procurando combinar o perfil do candidato com a vaga ofertada.

A entrevista é o método usado por $100 \%$ dos ETI para avaliar os candidatos. A avaliação dos hard skills é realizada por meio de perguntas técnicas e, em alguns casos, por provas práticas. Sobre a avaliação técnica, o Entrevistado 7 explicou o seguinte: "A entrevista voltada para o lado técnico onde ele [candidato] é testado a respeito dos conhecimentos que ele tem relacionados aos conceitos de gestão de projetos. Como ele conduz, por exemplo, a elaboração de um plano de comunicação [...]? Quais as análises de risco que ele faz?".

O processo de escolha do candidato também é influenciado pelas indicações, que é quando alguém da rede de relacionamento do ETI recomenda um nome para a vaga em 
questão. "A maioria dos profissionais que acabei contratando na minha carreira foram indicações ou de pessoas que trabalharam comigo ou de profissionais que já tinham trabalhado e estavam no mercado. De alguma forma, eu tentei pegar uma indicação da pessoa" (Entrevistado 10).

Há também a interferência das referências, que é quando o ETI recorre a ex-contratantes do candidato que possam dar informações sobre seu desempenho em empresas anteriores, muito embora esse procedimento não seja uma unanimidade. Os Entrevistados 10, 11 e 13 afirmam não confiar na técnica de solicitar referências dos candidatos, por suspeitar da sinceridade das recomendações ou por perceber a preocupação dos antigos empregadores em se isentar da responsabilidade da contratação do candidato. Há candidatos que citam contatos de amigos como referência profissional, o que pode induzir positivamente a opinião da referência.

Por último, a consulta às redes sociais é costumeiramente feita pelo ETI para compreender melhor quem é o candidato. Somando a essas formas de avaliação do candidato, há ainda a estratégia de decisão compartilhada, quando o ETI solicita a seus pares que o acompanhem nas entrevistas para haver um consenso na escolha do candidato. Tal prática foi citada por vários entrevistados. A esse respeito, o Entrevistado 7 disse: "Então a gente meio que costuma dizer que divide um pouco a responsabilidade. Então eu vou trazer um profissional para atuar em projetos na área de operações, então eu chamo o gerente de operações para entrevistar o profissional". O Entrevistado 16 informou que "Quando você põe 3 gerentes seniores entrevistando o GP [gerente de projetos] e eles aprovam, você tem o comprometimento de todos. Se o GP comete um erro lá na frente, [...] todos eles aprovaram a contratação".

\subsection{Desafios na Contratação do GPTI}

O processo de contratação, de uma maneira geral, é tido como desafiador pelos ETI. $\mathrm{Na}$ opinião deles, é difícil analisar os candidatos à vaga por um curto prazo e extrair desta análise todas as informações requeridas pela vaga. Há ainda outro agravante que é a falta de planejamento das contratações. As empresas, em geral, se preocupam em contratar quando seus recursos estão exíguos ou quando o projeto está na iminência de iniciar. Com base neste contexto, os principais desafios na contratação dos GPTI evidenciados na fala dos 16 entrevistados, podem ser resumidos conforme a seguir: 
$1^{\circ}$ Desafio - A entrevista não é suficiente para avaliar os candidatos

Os 16 entrevistados alegaram usar o método de entrevista para avaliar seus candidatos à vaga de GPTI. Entretanto, eles citaram que o tempo de duração da entrevista (em geral uma hora) é o fator de maior desafio, pois não conseguem avaliar o candidato de maneira assertiva em pouco tempo. Além disso, soma-se o fato de que os candidatos estão $100 \%$ concentrados na conquista da vaga e isso os leva, muitas das vezes, a assumir perfis que não são verdadeiramente os seus.

O Entrevistado 2 referiu-se a essa dificuldade: "É muito difícil você, numa entrevista de 30, 40 minutos, uma hora, você identificar coisas. Porque a pessoa [candidato] vem [para a entrevista]. Qual é o objetivo do candidato? Ganhar a vaga! Então, tudo que você perguntar, ele vai querer responder pro lado positivo". Já o Entrevistado 9 comentou "Porque tem gente que consegue se portar muito bem no processo seletivo e depois, no dia a dia, você fala assim: é outra pessoa!". O Entrevistado 8 corrobora: "Eu tive uma contratação recente de gerente de projetos e passaram umas 10 pessoas. Eu fiquei com dúvida em todos. Exatamente por não conseguir medir o perfil. Não ficou muito claro! A pessoa até tentava se vender, mas muito raso. Quando você começava perguntar, pedir exemplos, pedir situações que ela viveu, como ela agiria, elas pipocam.”

$2^{\circ}$ Desafio - Dificuldades em identificar o perfil do requisitante do projeto

Os ETI comumente contratam GPTI para atuarem em projetos cujos requisitantes pertencem a outras áreas de negócio da organização. Então, um ponto chave na contratação é entender o perfil do requisitante do projeto para que haja uma combinação deste com o perfil do GPTI. Gerentes de projetos reguladores, que seguem um método de gerenciamento de projetos de forma fiel, não combinam com empresas em um ritmo mais frenético, voltadas a resultados. Portanto, não conhecer bem o lado requisitante do projeto, poderá levar o ETI a fazer uma má contratação do GPTI.

Há ainda situações em que o GP é contratado para gerenciar múltiplos projetos de múltiplas áreas de negócios. Neste caso, se torna mais eficiente conhecer bem a cultura da empresa onde o GP atuará. Essa relação de sinergia entre o requisitante do projeto e o GP foi citada como o segundo fator mais desafiador na hora de contratar o GPTI. Quanto a isso, o Entrevistado 03 mencionou: "O meu cliente é um cara super estruturado, quer terminar tudo no horário e ir embora. E o gerente de projetos é aquele que fica aqui divagando, tal. Eu 
falo: gente não dá!". O Entrevistado 10 complementa: "Cada empresa dessas tem uma característica interna e exige um profissional diferente, e um profissional que é bem-sucedido em um desses clientes, às vezes não é no outro."

Ainda há casos em que o próprio requisitante do projeto desconhece o perfil de GP que ele precisa. O ETI recebe a solicitação de contratar um profissional cuja descrição da vaga não está muito clara, cabendo a ele investigar melhor o perfil do solicitante do projeto e a natureza do projeto em si para detalhar o perfil da vaga. "O principal desafio é entender a demanda do cliente. Quando ele te joga um job description e você vai em busca desse candidato, e aí, quando você acredita que você encontrou o candidato, você percebe que o job description não tem aderência com aquilo que o cliente realmente necessita. Então, o principal desafio não tá nem no candidato muitas vezes, tá mesmo em quem tá buscando o profissional." (Entrevistado 12).

$3^{\circ}$ Desafio - Encontrar gerentes de projetos de TI com hard skills e soft skills balanceados

Encontrar profissionais com uma combinação equilibrada de hard skills e soft skills é a terceira maior dificuldade mencionada pelos ETI na contratação dos GPTI. Agrega-se a este item a questão do orçamento disponível para contratar o GPTI. Foi o que explicou o Entrevistado 15: "O maior desafio pra mim é conseguir equilibrar a experiência requerida pra aquela função, daquele projeto, com um perfil adequado e que seja adequado tanto no nível de experiência, quanto comportamento, quanto à expectativa de salários. Então, é fazer essa tríade, eu acho que é o grande desafio".

Algumas empresas fecham o orçamento do projeto, incluindo os custos da contratação do GPTI, na venda do projeto para o cliente. No momento de contratar, o ETI é surpreendido com candidatos cuja expectativa salarial é maior que o orçamento da vaga. Neste caso, podem ocorrer diminuições no nível de exigência da vaga: o que seria a contratação de um GP sênior passa a ser uma contratação de nível pleno ou júnior e o ETI terá que dispor de tempo e dinheiro para desenvolver este profissional. A contratação do GPTI também pode sofrer limitações no nível de exigência imposto pelo ETI: “Ás vezes dentro do salário que você tem, do que já foi negociado e a empresa quer que você contrate, você nunca acha ninguém bom. Ninguém que você realmente gosta, então você tem que escolher o menos ruim" (Entrevistado 11). 
Nessa seara do hard skill e soft skill, os ETI demonstram maior preocupação no quesito soft skills por entenderem que este é mais difícil de avaliar no processo de contratação. O Entrevistado 14 afirmou: "O maior desafio é justamente a parte de soft skills. Eu tenho convicção que o determinante do sucesso do gerente de projetos é muito mais o soft skill do que os conhecimentos técnicos de gestão de projetos ou mesmo de TT'. Os ETI alegaram também a ausência de competências soft skills nos candidatos à vaga de GPTI. Alguns ETI demonstraram um conformismo quanto a essa deficiência: "O gerente de projetos entra num desgaste. Ele não sabe apresentar os problemas para o cliente ou não sabe lidar com esses problemas com o cliente da forma que deveria. Mas a gente não pega muito nisso na contratação. A gente sabe que isso vai acontecer" (Entrevistado 4). Este mesmo cenário é encontrado na fala do Entrevistado 16: "A maioria dos gerentes de projetos na área de TI, eles são muito bons tecnicamente. Mas, na hora que eles têm que passar por uma crise, ou tem que conversar com o cliente, conversar com o CEO, ou tratar até com a equipe, falta esse lado, falta muito".

$4^{\circ}$ Desafio - Conviver com as deficiências da área de RH

Os ETI demonstraram um descontentamento com relação às avaliações entregues pela área de RH, em geral realizadas superficialmente. Os motivos extraídos dos discursos dos ETI são: (1) o RH tem conhecimento raso sobre o negócio da empresa e a área de TI; (2) o RH faz análises rasas do perfil dos candidatos o que não contribui para o processo decisório dos ETI; (3) o RH se isenta da responsabilidade de escolha do novo GPTI das empresas, transferindo os riscos da má contratação para o ETI; (4) o RH, por vezes, não confirma as informações contidas no currículo do candidato para garantir que seu perfil esteja alinhado com a vaga; e, (5) o RH, por ser uma área corporativa nas empresas, acaba por assumir a responsabilidade de contratar desde estagiários, analistas, coordenadores, gerentes até diretores, o que torna um alto volume de trabalho que a área não consegue absorver. A consequência deste cenário é a sobrecarga de trabalho que os ETI precisam assumir na contratação do GPTI.

Trechos de falas dos ETI atestam essa situação: "O RH onde eu trabalhei era muito fraco [...] Então, eu acabava usando o RH mais pra essa triagem de salário [...] Não, eu não considerava a opinião deles até porque o que eles capturariam de um profissional que o desabonasse, eu com certeza, capturaria. Um cara louco. Um cara com falta de bom senso" (Entrevistado 10). O Entrevistado 4 reforça: “Tem uma pessoa especializada e dedicada [no $\mathrm{RH}]$, mas ela fala que ela não tem condição de avaliar todos os currículos de todas as posições 
que existem. Então, a gente [ETI] avalia as veracidades das informações do currículo". Para o Entrevistado 3: "Eu brinco que o RH vê se a pessoa não baba!"

Todos os ETI reconhecem a complexidade inerente ao processo de contratação do GPTI, principalmente no que tange a identificar o melhor perfil dentre os candidatos disponíveis e realizar a melhor combinação com a vaga oferecida. 0 Entrevistado 3, ao ser questionado sobre erros em contratações anteriores do GPTI, afirmou: "Já errei várias vezes". E em conformidade com esse achado, o Entrevistado 15 disse que "[...] a maior lição pra mim quando a gente erra é corrigir o erro o mais rápido possível". De fato, tais afirmações demonstram que a contratação do GPTI apresenta falhas em seu processo.

\subsection{Competências do GPTI}

Quando questionados sobre as competências do GPTI, os entrevistados elencaram dois requisitos que usualmente verificam na contratação: os técnicos ou hard skills, e os pessoais ou soft skills. Segurno o Entrevistado 15, "Eu dividiria em 2 grupos de competências chaves. Primeiro, as competências técnicas [...] relacionadas à gestão de projetos mesmo[...] e um outro conjunto de competências que a gente chama de soft skills, que é aquela competência do cara realmente lidar com os membros do projeto, com os stakeholders".

Ao avaliar as respostas dos ETI, foi possível criar uma lista com 59 competências. Uma análise de frequência foi realizada sobre a quantidade de citações das competências do GPTI pelos ETI e o resultado mostrou que: 83\% (296 de um total de 357 citações) de competências referenciaram soft skills e 17\% (61 citações) fizeram alusão aos hard skills. Tais competências foram ranqueadas das mais citadas para as menos citadas (a lista completa pode ser solicitada via email para o primeiro autor). Dentre as 10 competências mais citadas, oito são soft skills e apenas duas são hard skills, conforme demonstra a Tabela 1.

Tabela 1 - Ranking das competências do GPTI na opinião dos ETI

\begin{tabular}{|c|l|c|c|c|}
\hline Ranking & Competências do Gerente de Projetos de TI & Citações & \% & SS ou HS \\
\hline $1^{\circ}$ & Comunicação & 45 & $12,61 \%$ & SS \\
\hline $2^{\circ}$ & Relacionamento Interpessoal & 29 & $8,12 \%$ & SS \\
\hline $3^{\circ}$ & Liderança & 24 & $6,72 \%$ & SS \\
\hline $4^{\circ}$ & Atitude & 19 & $5,32 \%$ & SS \\
\hline $5^{\circ}$ & Flexibilidade & 15 & $4,20 \%$ & SS \\
\hline
\end{tabular}




\begin{tabular}{|c|l|c|c|c|}
$6^{\circ}$ & Experiência com Gestão de Projetos & 14 & $3,92 \%$ & HS \\
\hline $7^{\circ}$ & Gestão do Cliente & 12 & $3,36 \%$ & SS \\
\hline $8^{\circ}$ & Certificação em Gestão de Projetos & 11 & $3,08 \%$ & HS \\
\hline $9^{\circ}$ & Empatia & 11 & $3,08 \%$ & SS \\
\hline $10^{\circ}$ & Gestão de Conflitos & 11 & $3,08 \%$ & SS \\
\hline
\end{tabular}

Fonte: Elaborado pelos autores com base nas entrevistas

Os hard skills do GPTI mais mencionados pelos entrevistados desta pesquisa podem ser conferidos na Tabela 2.

Tabela 2 - Ranking dos hard skills do GPTI na opinião dos ETI

\begin{tabular}{|c|l|c|}
\hline Ranking & Hard Skills & Citações \\
\hline $1^{\text {o }}$ & Experiência com Gestão de Projetos & 14 \\
\hline $2^{\text {o }}$ & Certificação em Gestão de Projetos & 11 \\
\hline $3^{\circ}$ & Metodologias em Gestão de Projetos & 7 \\
\hline $4^{\mathrm{o}}$ & Formação Acadêmica & 5 \\
\hline $5^{\circ}$ & Conhecimento em Tecnologias & 3 \\
\hline $6^{\circ}$ & Conhecimento de Negócio & 3 \\
\hline $7^{\circ}$ & Gestão de Riscos & 3 \\
\hline $8^{\circ}$ & Habilidade com Outro Idioma & 2 \\
\hline $9^{\circ}$ & Habilidade com Projetos de Tecnologia & 1 \\
\hline $10^{\circ}$ & Controle Orçamentário & 3 \\
\hline
\end{tabular}

Fonte: Elaborado pelos autores com base nas entrevistas

Os soft skills mais mencionados pelos ETI entrevistados foram Comunicação, Relacionamento Interpessoal e Liderança. A Tabela 3Erro! Fonte de referência não encontrada. mostra os top 10 soft skills resultantes.

Tabela 3 - Ranking dos soft skills do GPTI na opinião dos ETI

\begin{tabular}{|l|l|c|}
\hline Ranking & Soft Skills & Citações \\
\hline
\end{tabular}




\begin{tabular}{|l|l|c|}
$1^{\circ}$ & Comunicação & 45 \\
\hline $2^{\circ}$ & Relacionamento Interpessoal & 29 \\
\hline $3^{\circ}$ & Liderança & 24 \\
\hline $4^{\circ}$ & Atitude & 19 \\
\hline $5^{\circ}$ & Flexibilidade & 15 \\
\hline $6^{\circ}$ & Gestão do Cliente & 12 \\
\hline $7^{\circ}$ & Empatia & 11 \\
\hline $8^{\circ}$ & Gestão de Conflitos & 11 \\
\hline $9^{\circ}$ & Negociação & 11 \\
\hline $10^{\circ}$ & Solução de Problemas & 11 \\
\hline
\end{tabular}

Fonte: Elaborado pelos autores com base nas entrevistas

\section{Discussão dos Resultados}

As entrevistas desta pesquisa demonstraram que o processo de contratação do GPTI é realizado por meio de três etapas: (1) Definição do perfil da vaga; (2) Divulgação da vaga; e, (3) Avaliação dos candidatos pelos ETI. Tais achados estão em consonância com o que dizem alguns pesquisadores (Petersen, Saporta and Seidel, 2000) ao citarem que a contratação deve envolver uma série de triagens e não um único evento, para evitar vieses.

Fernandez e Weinberg (1997) tratam da influência dos laços sociais na contratação de candidatos e constataram que as referências aumentam as chances de sucesso no processo de contratação. O vínculo social é um canal para obter informações difíceis de serem obtidas, o que contribui para melhores decisões. O uso de referência, embora tenha sido recomendado pela literatura, aparece em nossa pesquisa com parcimônia. O ponto crucial reside sobre o grau de confiabilidade do contato social: quanto mais confiável, maior é o respaldo.

Identificou-se que o papel de redes sociais - LinkedIn foi a mais citada - como um importante meio divulgador das informações acerca das vagas do GPTI, apoiando o processo de contratação tanto para quem procura emprego quanto para quem o oferece (Petersen, Saporta and Seidel, 2000). Os resultados não apontam o uso de caçadores de talentos (headhunters) pelos ETI para recrutar seus GPTI. Entretanto, é de se esperar que a qualidade média dos candidatos recrutados pelos caçadores de talentos seja consideravelmente superior à dos outros candidatos (Petersen, Saporta and Seidel, 2000). 
Um tema identificado na literatura e está alinhado com esta pesquisa é o prazo curto destinado para o processo de contratação. Kulik et al. (2007) reconhecem que os tomadores de decisão sofrem pressão de prazo para avaliar um número alto de pretendentes à vaga. Os ETI entrevistados demonstraram dispor de pouco tempo para se dedicarem ao processo de contratação, bem como, sofrer pela falta de planejamento: a vaga só é aberta quando a empresa chega no limite de sua capacidade.

Os ETI entrevistados, assim como os executivos americanos da pesquisa de Stevenson e Starkweather (2010), preferem os soft skills do GPTI aos hard skills no momento da contratação. Comparou-se o ranking de soft skills do GPTI de Stevenson e Starkweather (2010) com o ranking de soft skills decorrente dos 16 ETI e identificou-se uma convergência nos resultados (Figura ). Os números 1 e 2 do ranking de Stevenson e Starkweather (2010) ocuparam a posição 3 e 1, respectivamente, do ranking desta pesquisa. Os demais soft skills de Atitude e Flexibilidade também permaneceram entre os 6 mais citados neste estudo. A principal diferença é que nesta pesquisa os ETI brasileiros mencionaram mais o soft skill de Relacionamento Interpessoal.

\begin{tabular}{|c|c|c|c|}
\hline \multicolumn{2}{|c|}{ Stevenson e Starkweather (2010) } & \multicolumn{2}{|c|}{ Executivos de TI } \\
\hline Ranking & Soft skills & Ranking & Soft Skills \\
\hline 10 & Liderança & $1^{\circ}$ & SS - Comunicação \\
\hline $2 \circ$ & Habilidade de comunicação em múltiplos níveis organizacionais & $2^{\circ}$ & SS - Relacionamento Interpessoal \\
\hline $3 \underline{2}$ & Habilidade verbal & $3^{\circ}$ & SS - Liderança \\
\hline $4 \underline{2}$ & Habilidade escrita & $4^{\circ}$ & SS - Atitude \\
\hline 50 & Atitude & $5^{\circ}$ & SS - Flexibilidade \\
\hline \multirow[t]{5}{*}{60} & Capacidade em lidar com ambiguidade e mudança. & $6^{\circ}$ & SS - Gestão do Cliente \\
\hline & & $7^{\circ}$ & SS - Empatia \\
\hline & & $8^{\circ}$ & SS - Gestão de Conflitos \\
\hline & & $9^{\circ}$ & SS - Negociação \\
\hline & & $10^{\circ}$ & SS - Solução de Problemas \\
\hline
\end{tabular}

Figura 1. Comparação dos soft skills entre os rankings de Stevenson e Starkweather (2010) e as entrevistas com os ETI

Fonte: Elaborada pelos autores

Quando Araujo et al. (2016) citam que “...selecionadores não utilizam modelos plenamente racionais de decisão em processos seletivos, mas sim modelos considerados plenamente satisfatórios" (p. 696), idiossincrasias foram encontradas na presente pesquisa em acordo com a literatua. As entrevistas com os ETI mostraram que o processo de contratação do GPTI é baseado nas características individuais subjetivas do candidato, o que torna a avaliação irracional e enviesada que pode culminar em decisões de contratações equivocadas 
nas organizações. Testes de personalidade como o MBTI (Coda and Ricco, 2010) são pouco usados pelos ETI. O resultado desse cenário será o reforço das más estatísticas de falhas em projetos no setor de TI.

\section{Contribuições}

\subsection{Contribuições para a Academia}

Ao expandir o conhecimento sobre o fenômeno de contratação do GPTI sob a lente do ETI foi possível identificar os desafios citados na seção 4.2. O que mais nos chamou a atenção foi o distanciamento entre as áreas de TI e RH. Não se sabe se tal fato se repete em outras áreas corporativas da empresa, mas trata-se de uma questão a ser mais bem estudada por pesquisadores da área de gerenciamento de RH e GP. Nossa pesquisa confirmou a premissa inicial de que o ETI é o tomador de decisão no ato da contratação do GPTI, e o RH tem papel muito mais operacional e pouco estratégico.

Vale destacar que estudos que examinam tendências na publicação de gerenciamento de projetos concluíram que eles possuem um baixo nível de interesse em questões de gestão de RH e gestão de pessoas em grandes periódicos de gerenciamento de projetos (Keegan, Ringhofer and Huemann, 2017). Tal fato reflete a realidade, as empresas continuam investindo grandes quantias no recrutamento, seleção e treinamento de seus gerentes de projetos, mas o que se vê, na prática, é a necessidade de pesquisas voltadas para solucionar problemas reais com soluções perenes. A contratação do GPTI é um campo de pesquisa frutífero com espaço para melhorias.

\subsection{Contribuições para a Prática}

Este artigo pode ser útil para praticantes, pois apresenta uma lista de prescrições tanto para os ETI, quanto para os GPTI conforme será visto nas subseções seguintes.

\subsubsection{Prescrições para o ETI}

Seguem as prescrições para os ETI na intenção de fazer com que seus processos seletivos para as vagas de GPTI sejam bem-sucedidos. Tais passos foram extraídos das entrevistas desta pesquisa. 
Passo 1 - Definição do perfil da vaga do GPTI

Imagine o projeto que será gerenciado e todas as suas características, incluindo o perfil do solicitante. Na sequência, visualize o GP gerenciando o referido projeto no dia a dia. Procure avaliar quais hard skills e, principalmente, quais soft skills são primordiais para o bom gerenciamento deste projeto. Para ajudar neste processo, alguns questionamentos podem ser sugeridos. Procure pensar na natureza do projeto: é um projeto mais técnico ou mais baseado no negócio? Os tipos de perfis das principais partes interessadas: são pessoas mais facilitadoras e fáceis de lidar ou trata-se de pessoas mais temperamentais de difícil relacionamento? O projeto requer um conhecimento muito específico? Qual será o papel do novo GP: ele terá que montar a equipe? O escopo já foi definido? Ele fará um papel de maior protagonismo ou ficará mais a cargo de atividades operacionais? Anote este perfil que será o perfil da vaga do GPTI e compartilhe com pares e, principalmente, com o patrocinador do projeto. Refine este perfil até que você entenda que chegou à versão final. Publique a vaga por meio de seu canal de divulgação de vagas já institucionalizado: LinkedIn, intranet, redes sociais etc.

Passo 2 - Seleção dos currículos

Se possível, terceirize a triagem dos currículos ao seu departamento de RH ou a uma consultoria especializada. Peça para essa área avaliar os currículos de acordo com o descrito no perfil da vaga, realizando sondagens de mercado, quer seja por meio de referências ou por meio de indicações. A análise do currículo deve ir além do que está escrito, pois é sabido que os candidatos, eventualmente, por desejar muito lograr a vaga, podem falsear as informações curriculares. Se a sua empresa faz uso de testes psicológicos nesta etapa, peça o laudo conclusivo dos candidatos. Se a vaga demandar um conhecimento técnico aprofundado, peça para o RH aplicar uma prova técnica que deverá ser elaborada e corrigida por especialistas da área de conhecimento técnico em questão.

Passo 3 - Entrevista com os candidatos

Reavalie os currículos pré-selecionados na etapa anterior, refaça as consultas externas como solicitação de indicações e checagens de referências para ratificar que estes são realmente os melhores currículos disponíveis por hora. Caso contrário, retorne ao passo anterior. Busque sua rede de relacionamento profissional e estenda as consultas para as redes sociais como: LinKedin, Facebook, etc. Consultas no Google também podem revelar muito de 
um candidato, conforme mencionou um entrevistado desta pesquisa. Em geral, os ETI entrevistam de 3 a 5 candidatos para cada processo seletivo da vaga de GPTI. Dedique tempo para as entrevistas, busque fazê-las em um ambiente mais informal para conhecer, de fato, quem é o seu candidato. Lembre-se que situações do cotidiano revelam muito da personalidade das pessoas. Realize técnicas de quebra-gelo no início da entrevista para estabelecer rapport inicial com os candidatos.

Passo 4 - Avaliação dos soft skills dos candidatos

Aprofunde as entrevistas com os candidatos. Combine técnicas para avaliar os soft skills dos candidatos. Por exemplo, faça perguntas situacionais e associe com a solicitação de uma apresentação no Power Point com tema livre. Dessa maneira, você poderá compreender como o futuro GPTI agirá em situações bem próximas da sua realidade organizacional. Aproveite o ensejo para dirimir todas as dúvidas, então, é bem importante que você se prepare antes de cada entrevista. Cada candidato tem uma história, então procure conhecê-la antes da entrevista para enriquecê-la. Porém, se dúvidas surgirem após a entrevista, faça nova bateria de entrevistas para resolvê-las. Anote suas impressões sobre o candidato durante a entrevista por 2 motivos: $1^{\mathrm{o}}$ - para não ficar refém da sua memória; e, $2^{\circ}$ - para documentar seu conhecimento empírico com o processo de contratação, muito importante para as próximas contratações. E opte por realizar as entrevistas com acompanhamento de pares para que a escolha do candidato à vaga seja feita em colegiado e, assim, com menos riscos de errar.

Passo 5 - Avaliação do GPTI pós-contratação

Feche o ciclo. Após a contratação do GPTI, realize um acompanhamento de suas atividades. Forneça sessões de tutoria com o funcionário para desenvolvê-lo. Meça o desempenho do GPTI com base em observações próprias, mas também a partir de avaliações de diferentes membros do time do projeto. Retroalimente as anotações feitas no momento da entrevista, agora com dados depreendidos da observação da atuação do GPTI e conclua se houve sucesso ou não na contratação. Em ambos os casos, busque documentar as lições aprendidas positivas e negativas que servirão de fundação para a melhoria contínua das contratações futuras. 


\subsubsection{Prescrições para o GPTI}

A presente pesquisa permitiu elaborar orientações também para os GPTI para que logrem sucesso em suas candidaturas nos processos de contratação. Os cinco passos abaixo foram extraídos a partir das 16 entrevistas desta pesquisa.

Passo 1 - Elaboração do currículo

Elaborar um currículo com informações que possam ser comprovadas. Busque a opinião de um especialista para garantir que o texto seja fluído e possua clareza na comunicação aos olhos de quem o ler. É de suma importância que não haja erros de português, que podem ser facilmente evitados com o bom uso de um processador de textos. O currículo deve possuir critério de apresentação das informações: pode ser das informações mais recentes para as mais antigas ou o contrário. O importante é que, uma vez escolhida, esta lógica deva ser respeitada ao longo de todo o documento. O foco do currículo deve ser os hard skills, uma vez que este é o primeiro critério de avaliação dos recrutadores, embora não seja o mais importante, conforme demonstrou os resultados desta pesquisa. Os GPTI devem informar o seu conhecimento técnico no currículo, tais como: (1) Formação acadêmica; (2) Experiências anteriores em gerenciamento de projetos; (3) Conhecimento em tecnologias; (4) Conhecimentos em idiomas; (5) Certificações voltadas para o gerenciamento de projetos; (6) Conhecimentos de negócio advindos de projetos anteriores; e, por último, dados pessoais, para que o ETI possa contatá-lo facilmente.

Passo 2 - Atenção às redes sociais

Cuide de suas redes sociais. Fotos ou comentários em redes sociais são analisados pelos ETI. Embora se trate de uma seara pessoal, existe a premissa de que uma pessoa leva muito de seus traços pessoais para dentro das organizações enquanto desempenham suas atividades. Conforme dito por um dos entrevistados, grupos de Whatsapp compostos por GPTI já compõem um meio de avaliação dos candidatos pelos ETI. Lembre-se: as suas redes sociais são uma extensão de você.

Passo 3 - Desenvolvimento dos skills

Procure desenvolver-se na carreira, tanto no lado hard skill quando no lado soft skill. Esta pesquisa mostrou que os ETI valorizam candidatos que possuam atitude (quarto no ranking do soft skill mais citado nesta pesquisa). Principalmente o GPTI que lida com 
tecnologias que mudam constantemente. Este estudo mostrou que os soft skills têm mais a ver com o que somos do que com o que conhecemos. Portanto, o desenvolvimento dos soft skills requer vontade genuína de mudar traços de personalidade, atitudes e comportamentos arraigados na postura profissional.

Passo 4 - Desenvolvimento dos soft skills

Faça uma autoanálise ou consulte a opinião de colegas de projetos com quem já tenha trabalhado para identificar seus soft skills faltantes. A nossa sugestão é compará-los com os resultados desta pesquisa. De acordo com a análise das entrevistas com os executivos de TI, os soft skills mais citados foram: $1^{\circ}$ - Comunicação; $2^{\circ}$ - Relacionamento interpessoal; $3^{\circ}$ Liderança; $4^{\circ}$ - Atitude; $5^{\circ}$ - Flexibilidade; $6^{\circ}$ - Gestão do cliente; $7^{\circ}$ - Empatia; $8^{\circ}$ - Gestão de conflitos; $9^{\circ}$ - Negociação e $10^{\circ}$ - Solução de problemas. Se você não possui soft skills pertencentes a esta lista, considere desenvolvê-los.

Passo 5 - Pratique a ética

Seja ético no processo de seleção. Mentiras ou tentativas de pessoalizar um perfil alheio não são bem-vistas pelos ETI. Faça uso de uma boa comunicação na entrevista, os ETI buscam bem mais que respostas certas, mas respostas que demonstrem uma maturidade em lidar com situações difíceis ou até mesmo desconhecidas pelos GPTI. Pontualidade e boa apresentação pessoal são princípios básicos para a boa avaliação do candidato. E seja sincero, assumir erros é muito bem avaliado pelos ETI que buscam profissionais com bagagens sortidas de boas e más lições aprendidas em projetos, conforme explicou o Entrevistado 2.

\section{Considerações Finais}

Essa pesquisa objetivou apresentar as etapas do processo de contratação do GPTI sob a ótica do ETI. Por meio da abordagem qualitativa, realizou-se entrevistas em profundidade com 16 ETI brasileiros de diferentes segmentos de negócio. O o processo de contratação do GPTI está suscetível a falhas devido ao seu caráter subjetivo e natureza pouco acurada. Por mais que os ETI se esforcem na tomada de decisão na contratação do candidato à vaga do GPTI, há muitas questões que deixam o processo vulnerável. Alguns desafios foram apresentados referentes a tal processo, sob a ótica do ETI, como: (1) A entrevista não é o suficiente para avaliar o candidato; (2) Dificuldades em identificar o perfil do requisitante do projeto; (3) Encontrar GPTI com hard skills e soft skills balanceados; e, (4) Conviver com as 
deficiências da área de RH. Este artigo demostrou os hard skills e os soft skills mais demandados pelos ETI na hora de contratar um GPTI. E, assim, pôde-se compreender que os ETI dão preferência por candidatos com soft skills em detrimento dos hard skills. Os três soft skills mais mencionados nas entrevistas foram: $\left(1^{\circ}\right)$ Comunicação, $\left(2^{\circ}\right)$ Relacionamento Interpessoal e $\left(3^{\circ}\right)$ Liderança.

As limitações deste estudo foram conscientes. As entrevistas com uma amostra maior poderiam ter sido realizadas para aumentar a credibilidade dos resultados, mas entende-se que um número superior de entrevistas raramente agregaria novas informações relevantes aos achados da pesquisa. Pode-se destacar que um estudo entre diferentes regiões do Brasil poderia proporcionar um fator demográfico para comparações adicionais, pois esta pesquisa ocorreu apenas na região sudeste. Estudos em um segmento de indústria específico poderia convergir em resultados com maior similitude no processo de contratação, sem embargo, a nossa pesquisa ter vislumbrado um enfoque mais amplo da área de TI, independente do segmento de negócios da empresa.

Agendas de pesquisas futuras foram pavimentadas pelo atual estudo. Sugere-se a realização de artigo tecnológico que pudesse identificar uma solução e testá-la para os problemas identificados na contratação do GPTI. Estudos exploratórios adicionais poderiam ser realizados para avançar no entendimento de cada um dos desafios citados nesta pesquisa. Recomenda-se também um estudo sobre métodos de avaliação dos soft skills na contratação do GPTI tidos como essenciais pelos ETI para o sucesso do projeto.

As contribuições deste estudo revelaram prescrições para praticantes envolvidos no ato de admissão do GPTI. Em suma, o objetivo do artigo foi cumprido: explorou-se o fenômeno da contratação do GPTI sob a ótica do ETI e ficou evidenciada uma fragilidade em tal processo. Embora estudiosos da administração já falem sobre recrutamento e seleção há décadas, noticia-se aqui a necessidade de um olhar mais pragmático por partes dos pesquisadores na tentativa de dirimir os problemas expostos neste estudo.

\section{Referências}

Alam, I. (2005) 'Fieldwork and data collection in qualitative marketing research', Qualitative Market Research, 8(1), pp. 97-112. doi: 10.1108/13522750510575462.

Araujo, B. F. von B. de, Correa, F. and Wolters, M. (2016) 'O Sotaque Estadunidense 
Representa uma Vantagem em Decisões de Emprego no Brasil ?', RAC, Rio de Janeiro, 20(6), pp. 693-714.

Bandeira-de-Mello, R. (2006) 'Softwares em pesquisa qualitativa', in Métodos de coleta e análise de material empírico, pp. 429-460.

Bandeira-de-Mello, R. and Cunha, C. (2003) 'Operacionalizando o método da Grounded Theory nas Pesquisas em Estratégia: Técnicas e Procedimentos de Análise com apoio do Software Atlas/TI', Anais do Encontro de Estudos em Estratégias da Anpad, 1-18, p. 18. Bevilacqua, M. et al. (2014) 'Relation of project managers' personality and project performance: An approach based on value stream mapping', Journal of Industrial Engineering and Management, 7(4), pp. 857-890. doi: 10.3926/jiem.1005.

Blomquist, T., Farashah, A. D. and Thomas, J. (2016) 'Project management self-efficacy as a predictor of project performance: Constructing and validating a domain-specific scale', International Journal of Project Management. Elsevier Ltd, APM and IPMA, 34(8), pp. 1417-1432. doi: 10.1016/j.ijproman.2016.07.010.

Camarini, G. and Sousa, V. J. de (2006) 'As habilidades do gerente de projetos: um fator de sucesso para as organizações', REAd - Revista Eletrônica de Administração.

Cassar, R. and Martin, H. (2016) 'How to Choose a Project Manager under Uncertainty', in Proceedings of the 32nd Annual ARCOM Conference, pp. 619-628.

Charmaz, K. (2006) Constructing grounded theory: a practical guide through qualitative analysis, Book. doi: 10.1016/j.lisr.2007.11.003.

Cheng, M.-I., Dainty, A. R. J. and Moore, D. R. (2005) 'What makes a good project manager ?', Human Resource Management Journal, 15(1), pp. 25-37.

Coda, R. and Ricco, M. F. F. (2010) 'Estilos de Comportamento de Profissionais de Ciência, Tecnologia e Inovação (C,T\&I)', RAC, Curitiba, 14(3), pp. 516-531.

Creswell, J. W. (2010) Projeto de pesquisa: métodos qualitativo, quantitativo e misto. 3a. ed. Artmed.

Fernandez, R. M. and Weinberg, N. (1997) 'Sifting and Sorting: Personal Contacts and Hiring in a Retail Bank', eview, 62(6), pp. 883-902.

Gaddis, P. O. (1959) 'The project manager', in Harvard Business Review, pp. 348-353. doi: 10.1046/j.1537-2995.1980.20380214905.x.

Goodman, L. A. (1961) 'Snowball Sampling', The Annals of Mathematical Statistics, 32(1), pp. $148-170$.

Hauschildt, J., Keim, G. and Medcof, J. W. (2000) 'Realistic Criteria for Project Manager Selection and Development', Project Management Journal, 31(3), pp. 23-32. 
Havermans, L. et al. (2019) 'Rolling Into the Profession: Exploring the Motivation and Experience of Becoming a Project Manager', Project Management Journal, 50(3), pp. 115. doi: $10.1177 / 8756972819832782$.

Hays (2019) Análise de Tendências \& Salários do Brasil 2019.

Kang, D.-H. et al. (2005) 'Hiring the Right People and Management of Research Staff', Western Journal of Nursing Research, 27(8), pp. 1059-1066. doi: $10.1177 / 0193945905279926$.

Keegan, A., Ringhofer, C. and Huemann, M. (2017) 'Human resource management and project based organizing: Fertile ground, missed opportunities and prospects for closer connections', International Journal of Project Management. Elsevier Ltd and Association for Project Management and the International Project Management Association, pp. 113. doi: 10.1016/j.ijproman.2017.06.003.

Kulik, C. T., Roberson, L. and Perry, E. L. (2007) 'The multiple-category problem: category activation and inhibition in the hiring process', Academy of Management Review, 32(2), pp. 529-548.

Lima, L. F. (2016) O efeito da Inteligência Emocional nas Competências Interpessoais do Gerente de Projetos e no Sucesso da Gestão de Projetos. UNIVERSIDADE NOVE DE JULHO.

Mantovani, F. (2020) RH Guia Salarial 2020.

Midler, C. (1995) "'Projectification" of the firm: the Renault case', Scandinavian Journal Management, 11(4), pp. 363-375.

Napier, N. P., Keil, M. and Tan, F. B. (2009) 'IT project managers' construction of successful project management practice: A repertory grid investigation', Information Systems Journal, 19, pp. 255-282. doi: 10.1111/j.1365-2575.2007.00264.X.

PageGroup (2019) Guia de Salários 2019.

Pant, I. and Baroudi, B. (2008) 'Project management education: The human skills imperative', International Journal of Project Management, 26(2), pp. 124-128. doi: 10.1016/j.ijproman.2007.05.010.

Paton, S., Hodgson, D. and Cicmil, S. (2010) 'Who am I and what am I doing here? Becoming and being a project manager', Journal of Management Development, 29(2), pp. 157-166.

Petersen, T., Saporta, I. and Seidel, M. D. L. (2000) 'Offering a Job: Meritocracy and Social Networks', American Journal of Sociology, 106(3), pp. 763-816.

Pinto, J. K., Patanakul, P. and Pinto, M. B. (2015) 'Gender Biases in Hiring Project Revista Gestão e Secretariado (GeSec), São Paulo, SP, 12(1), jan./abr., 2021, p. 231-257. 
Managers: Perceptions of Trust and Likeability', IEEE Transactions on Engineering Management, 62(3), pp. 325-334. doi: 10.1109/TEM.2015.2415251.

Pinto, J. K., Patanakul, P. and Pinto, M. B. (2017) “"The aura of capability”: Gender bias in selection for a project manager job', International Journal of Project Management. Elsevier Ltd and Association for Project Management and the International Project Management Association, 35(3), pp. 420-431. doi: 10.1016/j.ijproman.2017.01.004.

PMI (2017) Guia do Conhecimento em Gerenciamento de Projetos (Guia PMBOK). 6a edição. Chicago.

Prado, E. P. V. and Takaoka, H. (2002) 'Os Fatores que Motivam a Adoção da Terceirização da Tecnologia de Informação: uma Análise do Setor Industrial de São Paulo', RAC, 6(3), pp. 129-147.

Richardson, T. M., Earnhardt, M. P. and Marion, J. W. (2015) 'Is Project Management Still an Accidental Profession? A Qualitative Study of Career Trajectory', Sage Open, 5(1).

Shenhar, A. J. et al. (2001) 'Project Success: A Multidimensional Strategic Concept', Long Range Planning, 34(6), pp. 699-725. doi: 10.1016/S0024-6301(01)00097-8.

Shenhar, A. J. et al. (2007) Linking Project Management to Business Strategy, Management. Project Management Institute, Inc.

Singh, R., Keil, M. and Kasi, V. (2009) 'Identifying and overcoming the challenges of implementing a project management office', European Journal of Information Systems. Palgrave Macmillan, 18(5), pp. 409-427. doi: 10.1057/ejis.2009.29.

Skulmoski, G. J. and Hartman, F. T. (2010) 'Information systems project manager soft competencies: a project-phase investigation', Project Management Journal, 41(1), pp. 61-80. doi: 10.1002/pmj.

Stevenson, D. H. and Starkweather, J. A. (2010) 'PM critical competency index: IT execs prefer soft skills', International Journal of Project Management, 28(7), pp. 663-671. doi: 10.1016/j.ijproman.2009.11.008.

Uzoka, F.-M. et al. (2018) 'Critical IT Project Management Competencies: Aligning Instructional Outcomes with Industry Expectations', International Journal of Information Technology Project Management, 9(4), pp. 1-16. doi: 10.4018/IJITPM.2018100101.

Submetido em: 13.07 .2020

Aceito em: $\quad 07.09 .2020$ 